\title{
GOVERNANÇA CORPORATIVA: FERRAMENTA PARA MITIGAR OS CONFLITOS DE AGÊNCIA
}

\author{
Nome \\ Antonielle Pagnussat \\ Instituição/Afiliação \\ Ajes - Faculdade do Vale do Juruena \\ País \\ Brasil \\ Resumo da \\ Biografia \\ Coordenadora dos cursos de Ciências Contábeis e Administração da Faculdade do \\ Vale do Juruena. \\ Graduada em Ciências Contábeis pela UNEMAT. \\ Especialista em Auditoria, controladoria e finanças pela Faculdade do Vale do \\ Juruena. \\ Mestranda em Contabilidade Gerencial pela Fucape Business School. \\ Contato principal para correspondência.

\begin{tabular}{|c|c|}
\hline Nome & Camila Alves de Moraes \\
\hline Instituição/Afiliação & Faculdade do Vale do Juruena - AJES, Juina - MT, FONE (66) 35661875 \\
\hline País & Brasil \\
\hline $\begin{array}{l}\text { Resumo da } \\
\text { Biografia }\end{array}$ & $\begin{array}{l}\text { Acadêmica do Curso de Ciências Contábeis da Faculdade do Vale do Juruena - } \\
\text { AJES, Juina - MT, FONE (66) } 3566 \text { 1875, e-mail: camilacontabeis326@gmail.co }\end{array}$ \\
\hline Nome & Maysa Oliveira de Melo Antonio \\
\hline Instituição/Afiliação & $\begin{array}{l}\text { Universidade do Estado de Mato Grosso - UNEMAT, Nova Mutum - MT, Fone (65 } \\
33712100\end{array}$ \\
\hline País & Brasil \\
\hline $\begin{array}{l}\text { Resumo da } \\
\text { Biografia }\end{array}$ & $\begin{array}{l}\text { Mestranda em Contabilidade Gerencial pela Fucape Busines School, Professora } \\
\text { Universidade do Estado de Mato Grosso - UNEMAT, Nova Mutum - MT, Fone (65 } \\
33712100 \text { e-mail: maysa-oliveira23@hotmail.com }\end{array}$ \\
\hline Nome & Weslayne da Silva Dias $\overline{\underline{\underline{E}}}$ \\
\hline Instituição/Afiliação & Faculdade do Vale do Juruena - AJES, Juina - MT, FONE (66) 35661875 \\
\hline País & Brasil \\
\hline $\begin{array}{l}\text { Resumo da } \\
\text { Biografia }\end{array}$ & $\begin{array}{l}\text { Acadêmica do Curso de Ciências Contábeis da Faculdade do Vale do Juruena - } \\
\text { AJES, Juina - MT, FONE (66) } 3566 \text { 1875, e-mail: weslaynedias21@gmail.com }\end{array}$ \\
\hline
\end{tabular}

\section{RESUMO}

Este estudo tem como objetivo verificar as principais vertentes das pesquisas relacionadas à Governança Corporativa, por meio de uma revisão bibliográfica, com dados qualitativos, utilizando artigos de periódicos nacionais e internacionais que tenham sido publicados a partir de 2012, classificados com Qualis Capes A1, A2 e B1. Com essa pesquisa é possível notar como a Governança Corporativa permeia os cenários empresariais, como essa ferramenta é fundamental para mitigar os conflitos de agência e ainda como pode ser utilizada para redução da evasão fiscal, responsabilidade social corporativa, entre outros. De acordo com a Teoria da Agência, os conflitos entre o agente e o principal decorrem da assimetria informacional 
existente entre eles o que causa insegurança nas relações. Tais conflitos podem ser reduzidos mediante demonstrações anuais e relatórios eficazes da auditoria.

Palavras-Chave: Agente; Principal; Conflito de Agência; Governança Corporativa.

\section{INTRODUÇÃO}

A temática abordada vem sendo discutida na atualidade, principalmente nas grandes corporações, ajudando a diminuir conflitos por meio da Governança Corporativa, que é concretizada por gestores bem qualificados, que buscam conhecer a realidade da empresa tendo em vista o mercado como cenário principal (NASSIF \& SOUZA, 2013). A Governança Corporativa incentiva as empresas a adotar boas práticas para combater os Conflitos de Agências, diminuir a assimetria informacional e consequentemente inibir as práticas de Gerenciamento de Resultado (CHEN, 2016; LAKSMI e KAMILA, 2018).

Conflito de agência é a possibilidade de divergência de interesses entre acionistas e gestores, onde um tenta tirar vantagens do outro de uma mesma situação. Uma maneira de minimizar tal conflito está ligada à através da publicação das contas anuais, relatórios da auditoria e, principalmente a Governança Corporativa. A Governança Corporativa constitui uma das possíveis formas de alinhar os interesses do principal e o do agente (NASSIF \& SOUZA, 2013).

Diferentes interesses dos agentes e dos diretores fazem com que ambas as partes tentem aumentar o lucro, pois serão remunerados a partir dele. Os diretores querem o maior número possível de retorno para seus investimentos, que são refletidos no aumento do dividendo em cada uma das ações que possuem (ANUP \& COOPER, 2017; SANAD \& SARTAWI, 2016; CHANG et. al. 2015). Os agentes querem que seu interesse seja acomodado com compensação adequada ou bônus pelo seu trabalho. Os diretores avaliam o desempenho dos agentes com base em sua capacidade de aumentar o lucro a ser alocado aos dividendos. Quanto maior o lucro, o preço da ação e o dividendo, mais bem sucedidos são os agentes, de modo que eles merecem maior incentivo (ANUP \& COOPER, 2017; SANAD \& AL-SARTAWI, 2016; CHANG et. al. 2015). 
Em relação à Governança Corporativa são diversos fatores que maximizam o potencial deste mecanismo, como Responsabilidade Social Corporativa (RSC) onde a empresa não tem foco apenas no capital, mas prioriza parte do seu tempo para sociedade (LAKSMI e KAMILA, 2018).

Tendo em vista a relevância do tema o objetivo da pesquisa é realizar um estudo sobre a Teoria da Agência relacionando-a com a mitigação dos conflitos nas organizações, e apontar mecanismos utilizados para solucionar esse tipo de conflito, verificando as principais vertentes das pesquisas relacionadas à Governança Corporativa, por meio de uma revisão bibliográfica, utilizando artigos de periódicos internacionais que tenham sido publicados a partir de 2012, e artigos nacionais abordando várias definições de Teoria da Agência e Governança Corporativa. Com essa pesquisa é possível notar como a Governança Corporativa permeia os cenários empresariais, e como essa ferramenta pode ganhar novos contornos dependendo do tipo de economia onde se aplique e também outros objetivos que vão além de mitigar os conflitos de agência, como por exemplo, redução da evasão fiscal, responsabilidade social corporativa, entre outros.

\section{REFERÊNCIAL TEÓRICO}

\subsection{TEORIA DE AGÊNCIA}

A teoria de agência relaciona-se com os problemas que surgem com a separação entre propriedade e controle, que tem origem nas diferentes motivações e objetivos, na assimetria de informação e nas diferentes preferências de risco que existem entre principal (proprietário) e os agentes (gestores) (NASSIF \& SOUZA, 2013).

Com o aumento do capital e o crescimento das entidades, o proprietário não tem o total controle sob a organização, portanto, esse papel passa a ser exercido pelos executivos e assim inicia-se o conflito entre o proprietário e os gestores. (NASSIF \& SOUZA, 2013).

Martinez (2001) e Souza (2013) investigaram as causas que levam o conflito de agência. O resultado da investigação mostra que o principal delega atividades aos agentes, que consequentemente tem o poder de decisão, sendo que o mesmo pode controlar os recursos 
econômicos da empresa, manipulando os resultados contábeis através do gerenciamento dos mesmos, que é formado por opções de escolhas discricionárias das normas contábeis ao gerente. Assim o agente realiza suas escolhas em busca de maximizar seus próprios objetivos que o levam a reportar um resultado diferente daquele que realmente é o concreto (MARTINEZ 2001; SOUZA, 2013).

Dentre os conflitos de agência apontados pela literatura, a assimetria informacional pode influenciar os acionistas, favorecendo o acionista maioritário, pois o mesmo detém informações privilegiadas usando-as em benefício próprio, desfavorecendo os acionistas minoritários (SANTOS, 2013). A teoria de agência baseia-se no argumento que o agente tem a informação ao seu favor, afetando o principal, pois, o mesmo não consegue monitorar as ações do agente devido à assimetria de informação entre as partes, assim nem sempre os seus interesses são devidamente acatados pelos agentes (SANTOS, 2013).

No contexto da Teoria de Agência uma maneira para equilibrar esses conflitos é por meio da relação formal, ou explicita, gerando uma obrigação legal, através de contratos acordados entre as partes envolvidas, em outras palavras esse acordo irá minimizar esses conflitos, pois, estarão expressos direitos e deveres sobre as ações dos proprietários e agentes (SILVA, SOUSA e LEITE, 2010).

Os conflitos entre proprietários e gestores podem, então, ser mais bem compreendidos a partir dos objetivos da empresa, e mais do que isso, a partir das forças que modelam tais objetivos ou que se tornam os elementos que condicionam a atuação dos gestores no sentido de reuni-los em torno dos interesses da organização. Alguns componentes determinam o estilo entendido como o mais apropriado para a administração do negócio, como: a missão, as crenças e valores do proprietário. (NASSIF \& SOUZA, 2013).

Uma das formas encontradas para solucionar o conflito de agência, é através dos mecanismos disponibilizados pela Governança Corporativa,Rughoobur (2018) de modo objetivo, conceitua Governança Corporativa como uma ferramenta utilizada para gerenciar e controlar apropriadamente a instituição, salvaguardando sobretudo o investimento do acionista (RUGHOOBUR, 2018). 


\subsection{GOVERNANÇA CORPORATIVA}

Em seus estudos Iny, Psaros e Seame (2018) mencionam a falta de evidências sobre a Governança Corporativa designadas a minimizar os conflitos de agência, destacando a relevância desta, principalmente para as organizações com desenvolvimento econômico comprometido.

Baseado na Governança Corporativa, Al-Sartawi (2016), aponta que é necessário para os acionistas e investidores verificarem as informações, é fundamental que suas demonstrações contenham números precisos e fidedignos, tendo em vista, minimizar os riscos associados as suas decisões, para que isso aconteça é essencial órgãos competentes, que a regulamentam, tais como: conselho administrativo, corpo diretivo, acionistas/investidores. Com isso, uma maneira de prosperar a situação econômica/financeira da empresa se dá pelo investimento em capital intelectual, melhorando questões de nível corporativo, modificando o tipo de gestão para questões estratégicas e políticas pertinentes com o foco em proteger investidores e usuários de informações financeira, minimizando falhas de agência. (AL-SARTAWI, 2016).

Para o crescimento da economia é necessária uma boa gestão, unindo conhecimento e boas práticas de Governança Corporativa, que consequentemente irão absorver informações relevantes e de tal modo tornar a decisão mais viável para a organização. A divulgação é uma parte essencial, para capturar funcionários talentosos, e também auxiliar a tomar a melhor decisão, empresas com uma boa Governança Corporativa tem maior tendência em ter um relacionamento agradável com os fornecedores e todas as partes envolvidas (AL-SARTAWI, 2016). Observa-se que os procedimentos citados seguem um ciclo contínuo, de um lado o capital intelectual, preocupando-se com a criação de valores de uma empresa e por outro lado a Governança Corporativa exercendo uma função de continuidade desse valor (AL-SARTAWI, 2016). O capital intelectual flui como um plano estratégico, consequentemente agregando valor a empresa, tornando-a mais bem-sucedida (AL-SARTAWI, 2016).

Buscando identificar a importância da Responsabilidade Social Corporativa (RSC), Laksmi e Kamila (2018) considera pertinente a responsabilidade da entidade sob aspectos 
sociais, que envolvem todas as partes interessadas, como a organização, o indivíduo ou grupo, que possam influenciar ou ser influenciada por várias decisões. Então, as instituições percebem a importância e a influência em adotar medidas referentes ao bem-estar social. As empresas que se atem a RSC, tem maior tendência de competitividade em relação a outras organizações do mesmo segmento, se destacando das empresas que não aderem RSC (LAKSMI e KAMILA, 2018).

Para a sobrevivência da corporação é vital a lucratividade, então, os gestores que são qualificados para este cargo, através de seu conhecimento, utilizarão sua instrução para beneficiar a empresa e todas as partes interessadas. Um exemplo é o gerenciamento de resultados, que trata da modificação dos relatórios contábil/financeiro conforme a legislação pertinente, resultando uma realidade financeira tendenciosa, ou seja, utilizando-se dos métodos contábeis, para satisfazer as necessidades dos investidores e dos gerentes (LAKSMI e KAMILA, 2018).

\subsection{Estudos Anteriores: Governança Corporativa e os Conflitos de Agência}

Atualmente, a Governança Corporativa é considerada uma ferramenta de gestão, que aliada às boas práticas, é capaz de mitigar os problemas de agência e a falta de simetria das informações (AL-SARTAWI, 2018). Em seus estudos, Chang et al. (2015) afirmam que adoção de boas práticas de governança Corporativa visam reduzir os problemas de agência decorrentes da relação entre acionistas e gestores, e portanto, empresas com mais qualidade de governança sofrem menos conflitos de agência, melhoram seu desempenho organizacional, reduzem a assimetria de informação e com isso melhoram seu valor de mercado.

A adoção de boas práticas de governança corporativa visa reduzir os problemas de agência decorrentes da relação entre acionistas e gestores, e, portanto, empresas com mais qualidade de governança sofrem menos conflitos de agência, melhoram seu desempenho organizacional, reduzem a assimetria de informação e com isso melhoram seu valor de mercado (CHANG et. al.2015). A Governança Corporativa tem sido reconhecida como um mecanismo 
para alcançar a máxima eficiência, sustentabilidade, produtividade e lucratividade dentro das empresas (ANUP \& COOPER, 2017; SANAD \& AL-SARTAWI, 2016).

Tomadores de decisão, como gestores, acionistas e potenciais investidores sempre buscam informações relevantes e precisas para minimizar os riscos associados às suas decisões (CHANG et al 2015). Assim, governos, empresas de auditoria e órgãos reguladores começaram a tomar medidas para melhorar sua estrutura de Governança Corporativa, levando ao público uma maior margem de segurança quanto à transparência da gestão (ALKHADASH \& ALSARTAWI, 2010; MOUSA \& DESOKY, 2012).

Consistente com essa visão, diversos autores da literatura internacional, relacionaram seus estudos ao tema (HERMASI, 2017; LAKSMI e KAMILA, 2018; ARMSTRONG et al., 2015; DETTHAMRONG et al., 2017; SHEHATA, 2016; SAUERWALD e PENG 2012; INYA, PSAROS e SEAMER, 2018).

Hemarsi (2017) averiguou o impacto da Governança Corporativa na estrutura de capital em empresas canadenses, e verificou que empresas com menor alavancagem de mercado, apresentam Governança Corporativa mais consistente, além disso, a autora evidenciou que a alavancagem é impactada de forma positiva pela política de divulgação, fato até então desconhecido na literatura.

Ao investigarem o efeito da boa Governança Corporativa, Laksmi e Kamila (2018) verificaram, em empresas de capital aberto da Indonésia, que gestão de resultados na divulgação da Responsabilidade Social Corporativa (RSC) é afetada positivamente pela propriedade gerencial, propriedade estatal e pelo comitê de auditoria. De forma contrária, os autores também encontraram que a estrutura do conselho de administração, o gerenciamento de resultados e a propriedade estrangeira, são elementos que não influenciam a divulgação da RSC.

Baseado na teoria contraintuitiva de Desai e Dharmapala (2006) sobre a correlação entre a escolha de evasão fiscal e a Governança Corporativa, Armstrong et al. (2015), examinaram como as decisões de planejamento tributário podem auxiliar a verificar se existe uma ligação entre os mecanismos de Governança Corporativa, incentivos fiscais e evasão fiscal das empresas. Os resultados encontrados pelos autores apontaram que existe uma relação negativa 
para índices mais elevados de evasão fiscal, e relação positiva entre independência do conselho e aprimoração financeira para índices menores de níveis de evasão fiscal (ARMSTRONG et al., 2015).

Quanto à contribuição da Governança Corporativa para a formação da estrutura de capital, Detthamrong et al. (2017), evidenciam que esta contribui positivamente para o acesso ao crédito, seja em países desenvolvidos ou em mercados emergentes.

Buscando investigar a Governança Corporativa no cenário de países que fazem parte do Conselho de Cooperação do Golfo (CCG), Shehata (2016), encontra que a Governança Corporativa ainda é considerada um novo conceito e que em países como os citados são necessários estudos mais aprofundados a respeito do assunto.

Levando em consideração que as práticas de Governança Corporativa vêm fazendo parte do cenário das empresas nas mais diversas partes do mundo, autores têm investigado se existe diferença de tais práticas em diferentes tipos de economia mundo a fora. É o caso de Sauerwald e Peng (2012), que questionaram se as práticas de Governança Corporativa prescritas para as economias ocidentais são relevantes para as economias emergentes no Sudeste Asiático. Inya, Psaros e Seamer (2018), não encontraram nenhuma relação entre os mecanismos de Governança Corporativa recomendados pelo Ocidente, como conselhos independentes, comitês de auditoria e separação dos papéis de CEO e presidente, e a probabilidade de redução de uma empresa com má conduta na Tailândia. Esses achados não são consistentes com a Teoria da Agência ou com a evidência empírica de estudos em economias desenvolvidas ocidentais.

Shiri et al. (2012) desenvolveram uma pesquisa para investigar se existe relação entre os mecanismos de Governança Corporativa e a qualidade do lucro das empresas listadas na Bolsa de Valores de Tehran. Os resultados da pesquisa mostram que as empresas que se encontram em categorias mais elevadas de Governança Corporativa melhoram significativamente a qualidade dos lucros, em contrapartida empresas com fraca Governança Corporativa são mais propensas a gerenciar lucros, a fim de atender ou superar as previsões dos analistas. 
Lattemann (2014) conduziu um estudo em empresas do Brasil, Rússia, Índia e China (BRIC) para verificar quais fatores afetam as práticas de Governança Corporativa desses países. Embora o autor tenha apresentado um número pequeno de melhores práticas de Governança (apenas 13), a pesquisa confirma que países do BRIC se adaptam melhor às práticas internacionais de Governança Corporativa, e que, portanto, as instituições internacionais influenciam positivamente as empresas do BRIC a aplicarem padrões internacionais de boa Governança Corporativa.

Uma boa Governança Corporativa possibilita o avanço de setores com maior exposição ao risco moral, enquanto a má Governança Corporativa desencadeia níveis mais baixos de concorrência e empresas com maior propriedade e alavancagem interna (FULGHIERI e SUOMINEN, 2012). Ao fazer tal afirmação, Fulghieri e Suominen (2012), mostraram que no mercado acionário a Governança Corporativa é fundamental, pois exerce interação com risco moral no mercado de dívida, e em uma economia, pode designar a estrutura financeira e industrial.

No que se refere às práticas de Governança para garantir a qualidade dos lucros divulgados, Sáenz González e García-Meca (2014) identificaram em um estudo com empresas da América Latina, que uma estrutura de governança fraca pode proporcionar oportunidades para que gestores desenvolvam certos comportamentos que acabariam por resultar em uma baixa qualidade de lucros divulgados e além disso, comprometer a ética nos negócios.

Baseando-se em relatos existentes na literatura sobre práticas desviantes de Governança Corporativa, Aguilera, Judce e Terjesen (2018), desenvolveram um conceito para verificar os motivos que levam as empresas a adotarem práticas que não estão em conformidade com a logicidade de Governança predominante no país, onde foi possível argumentar que os mecanismos de Governança em conformidade ou não com as práticas impostas, são mais possíveis de serem adotadas à medida em que se eleva a discrição da Governança de uma empresa. Aguilera, Judce e Terjesen (2018), relatam ainda, que o ambiente regulatório e a capacidade de Governança da organização, são fatores determinantes para adoção de uma prática de desvio de governança. 
A Governança Corporativa torna-se essencial para manter a empresa com relacionamento transparente, ético e produtivo entre as partes interessadas, sejam essas stakeholders, shareholders e agentes (AGUILERA et al., 2015). Nos Estados Unidos a propriedade, na maior parte das firmas, não possui alta concentração acionária e não existe uma separação clara entre propriedade, controle e gestão (AGUILERA et al., 2015). O fato de que aqueles que possuem a propriedade (acionistas), muitas vezes tem pouco controle sobre a gestão da empresa, faz com que os interesses dos gestores e dos acionistas não fiquem totalmente alinhados, assim sendo, aqueles que possuem uma maior participação no capital da empresa tendem a buscar seus próprios objetivos (ARMITAGE et al., 2017).

A Governança Corporativa possui componentes internos e externos, Baber et al. (2015), definem os fatores internos de governança como sendo os métodos utilizados pela administração da empresa e conselho administrativo da organização. Já os fatores externos de governança, são aqueles que tratam de provisões societárias e estatutárias, indicam os custos para os acionistas, e como consequência, desafia toda a supervisão da companhia, conselho e administração (BABER et al., 2015).

O Conselho de Administração e a Participação Acionária são considerados mecanismos internos de Governança Corporativa e a literatura cita ainda os mecanismos externos que contribuem para minimizar as falhas dos mecanismos internos. Os mecanismos externos são: sistema legal, mercado para o controle corporativo, auditoria externa, agências de rating, ativismo dos stakeholders e mídia (AGUILERA et al., 2015).

Samaha et al. (2012), desenvolveram um estudo sobre Governança Corporativa entre empresas egípcias, e afirmam que o existe um baixo nível de divulgação de tais práticas, exceto pelos itens obrigatórios que fazem parte das Normas Contábeis do Egito e recomendados pela Conferência das Nações Unidas sobre Comércio e Desenvolvimento, isso pode ser reflexo da falta de um marco regulatório para a contabilidade no Egito e também de outros problemas sociais que envolvem o país em questão.

Nesse sentido, Cohn (2013), retrata que os investidores ativistas configuram uma Governança Corporativa externa, onde normalmente acumulam pequenas participações, que 


\section{Revista

não lhes dão o direito de exercer o controle interno, fazendo com que tenham que acreditar na eficácia dos mecanismos internos de governança da instituição no momento de implementar mudanças. Dessa forma, no mercado corporativo, como meio para alterações nas políticas em companhias de capital aberto, o ativismo dos acionistas representa uma grandeza cada vez mais importante (COHN, 2013).

Liao, L. K., Mukherjee, T. \& Wang, W. (2015), conduziram um estudo empírico que buscou compreender o papel da Governança Corporativa na definição da estrutura de capital, observando empresas durante o período de 1996 a 2008. Na pesquisa descobriram que tanto um maior nível de alavancagem financeira quanto uma maior velocidade de ajuste de alavancagem para o nível desejado dos acionistas, estão associados a uma melhor qualidade de Governança Corporativa, definida por um conselho mais independente, com separação do CEO e maior presença de diretores externos, aliada à maior participação institucional. Em contrapartida, a remuneração de incentivo gerencial, em média, desestimula o uso de dívida ou ajustes em direção ao nível desejado dos acionistas, consistente com seu efeito de entrincheiramento. $\mathrm{O}$ efeito da Governança Corporativa sobre os ajustes de alavancagem é mais pronunciado quando a alavancagem inicial está entre o nível desejado pelo gerente e o nível desejado pelos acionistas, onde os interesses dos gerentes e dos acionistas entram em conflito. Nesse caso, os resultados dos estudos de Hemarsi (2017) são consistentes com os encontrados por Liao, L. K., Mukherjee, T. \& Wang, W. (2015).

Sáenz González \& García-Meca (2014), pesquisando empresas não financeiras latinoamericanas no período de 2006 a 2009 afirmam que embora estudos nos EUA e na Europa tenham documentado uma melhora na qualidade dos lucros associada a características de Governança Corporativa, a situação na América Latina é questionável, dado o ambiente de negócios em que as empresas operam, que é caracterizado pelo controle da propriedade familiar e fraca proteção legal. Os autores apontam ainda que no contexto latino-americano, o papel dos conselheiros externos é limitado e que os conselhos que se encontram com mais frequência assumem uma posição mais ativa inibindo assim o uso de práticas manipulativas com vistas a melhorar o resultado. 


\section{Revista

\section{CONSIDERAÇÕES FINAIS}

Diante das teorias mencionadas, tomando como base o relato de diversos autores, é possível afirmar que a Governança Corporativa é vista como uma importante ferramenta para minimizar conflitos de agência e ampliar o grau de confiabilidade nos mais diversos meios empresariais. A teoria de agência relaciona-se com os problemas que surgem com a separação entre propriedade e controle, que tem origem nas diferentes motivações e objetivos, na assimetria de informação e nas diferentes preferências de risco que existem entre principal (proprietário) e os agentes (gestores). A utilização da Governança Corporativa, por intermédio de boas práticas, tem sido de fundamental importância para todos os envolvidos com a entidade (investidores, acionistas, governo), e não apenas para gestores, uma vez que favorece a transparência nas organizações, o que também contribui para mitigar os problemas decorrentes dos conflitos de agência.

Para tanto, por meio dos princípios da transparência, equidade, prestação de contas e responsabilidade corporativa, a Governança Corporativa propicia a criação de ferramentas para controle interno e externo que permitem uma melhor execução dos negócios e atuam de forma a evitar que práticas ilícitas ou privilégios ocorram, o que garante proteção para os direitos de todas as partes interessadas.

Este estudo limitou-se a verificar, de forma geral, algumas das principais pesquisas que tratam de Governança Corporativa em diversos cenários e objetivos. Conclui-se que este é um tema bastante amplo e que os resultados encontrados pelos pesquisadores citados dependem muito do cenário onde o estudo foi realizado. Vale salientar que este é apenas um breve ensaio e que para melhor compreensão a respeito do tema outros estudos mais aprofundados são necessários.

\section{ABSTRACT}

This study aims to verify the main aspects of the researches related to Corporate Governance, through a bibliographical review, with qualitative data, using articles from national and international journals that have been published since 2012, classified with Qualis Capes A1, A2 and B1. With this research it is possible to notice how Corporate Governance permeates business scenarios, and how this tool is fundamental to mitigate agency conflicts and how it can be used to reduce tax evasion, corporate social responsibility, among others. According to 
the Agency Theory, the conflicts between the agent and the principal result from the informational asymmetry that exists between them which causes insecurity in the relations. Such conflicts can be reduced through annual and effective audit reports.

Keywords: Agent; Main; Conflict of Agency; Corporate governance.

\section{REFERÊNCIAS}

AlKhadash., Aldeen, H. e A-1Sartawi, A. Sarbanesoxley's ability to increase the independence of the certified public accountant in Jordan and its impact on reducing the audit expectation gap. An empirical investigation from the perspective of auditors and institutional investors. Jordan Journal of BusinessAdministration, v. 6 , p. 294-315, 2010.

Anup, A. \& Cooper, T. Consequences of corporate governance of accounting scandals: Evidence from Senior Management, CFO and Auditor's Turnover. Quarterly Journal of Finance, v. 7, p. 141, 2017.

Armitage, S., Hou, W., Sarkar, S., Talaulicar, T. Corporate governance challenges in emerging economies. Corporate Governance: an International Review, v. 25(3), p. 148154, 2017.

Aguilera, R. V., Desender, K., Bednar, M. K., \& Lee, J. H. Connecting the Dots - bringing external corporate governance into the corporate governance puzzle. The Academy of Management Annals, v. 9(1), p. 483-573, 2015.

Armstrong S.C. et al. Corporate governance, incentives, and tax avoidance. Journal of Accounting and Economics, v. 60, 2015.

Al-Sartawi, M. A., Corporate Governance and Intellectual Capital: Evidence from Gulf Cooperation Council Countries. Academy of Accounting and Financial Studies Journal ,v. 22, n 1, 2018.

Aguilera, R.V., Judge W. Q., Terjesen. Corporate Governance Deviance. Academy of Management Review, v. 43, n. 1, 87-109, 2018.

Baber R. W. et al. External Corporate Governance and Misreporting. Contemporary Accounting Research, v. 32, n. 4, pp. 1413-1442, 2015.

Chang, Y.-K., Chen, Y.-L., Chou, R. K. \& Huang, T.-H. Corporate governance, product market competition and dynamic capital structure. International Review of Economics and Finance, v. 38(1), p. 44-55, 2015.

Cohn J. B., Rajan U. Optimal Corporate Governance in the Presence of an Activist Investor. The Review of Financial Studies, v. 26, n. 4, pp. 985-1020, 2013.

Detthamrong, U., Chancharat, N. \& Vithessonthi, C. Corporate governance, capital structure and firm performance: evidence from Thailand. Research in International Business and Finance, v. 42(1), pp. 689-709, 2017. 
Desai, MA, Dharmapala, D. Avoid corporate taxes and high-powered incentives. Jornal da economia financeira, v. 79, p. 145-179, 2006.

Fulghieri, P. Suominen, M. Corporate Governance, Finance, and the Real Sector. The Journal of Financial and Quantitative Analysis, v. 47, n. 6, p. 1187-1214, 2012.

González S., García-Meca, E. Does Corporate Governance Influence Earnings Management in Latin. American Markets? Journal of Business Ethics, v. 121, n. 3, p. 419-440, 2014.

Hermasi, N. The Impacto f Corporate Governance on Capital Structure: A New Perspective. International Journal of Business and Economics Perspectives, v. 12, n. 1, 2017.

Inya, Puritud; Psaros, Jim, and Seamer, Michael. The Relevance of Western Corporate Governance in Mitigating Management Misconduct in Thailand. Emerging Markets Finance \& Trade, v. 54, p. 1425-1441, 2018

Lattemann, C. On the convergence of CG practices in emerging markets. International Journal of Emerging Markets, v. 9, n. 2, pp. 316-332, 2014.

Laksmi, C. A., Kamila, Z. The Effect of Good Corporate Governance and Earnings Management to Corporate Social Responsibility Disclosure. Academy of Accounting and Financial Studies Journal, v. 22, n 1, 2018.

Liao, L. K., Mukherjee, T. \& Wang, W. Corporate governance and capital structure dynamics: an empirical study. The Journal of Financial Research, v. 38(2), p. 169-191, 2015.

Martinez, Antonio Lopo. "Gerenciamento" de resultados contábeis: Estudo empírico das companhias abertas brasileiras. 2011. $154 \mathrm{f}$. Tese (Doutorado) - Curso de Contabilidade, Contabilidade e Atuária, Universidade de São Paulo Faculdade de Economia, Administração e Contabilidade, São Paulo, 2001. Cap. 8.

Mousa, GA \& Abdelmohsen MD. The association between internal mechanisms of governance and corporate value: Evidence from Bahrain. Asian Journal of Accounting and Finance Management, v. 8 (1), p. 67-92, 2012.

Rughoobur, Soujata. An Assesssment of good corporate governance in state owned enterprises of Mauritius. Studies in Business and Economics. V. 13 n. 1, 2018.

Sanad., Zakeya., AlSartawi. \& Abdalmuttaleb. Investigating the Relationship Between Corporate Governance and Financial Reports of the Internet (IFR): Evidence from Bahrain Bourse. Jordan Journal of Business Administration, v. 12 (1), p. 239-269, 2016.

Santos, Marília Medeiros. Teoria de Agência, Governo das Sociedades e Opinião do Auditor. 2013. 76 f. Tese (Doutorado) - Curso de Contabilidade, Instituto Superior de Contabilidade e Administração, São Paulo, 2013.

Sauerwald, S. e MW Peng. Informal institutions, shareholder coalitions and major conflicts. Asia Journal Pacific of Management v. 30 (3): p. 355-370, 2012.

Samaha, K., Dahawy, K., Hussainey, K., Stapleton, P. The Extent of Corporate Governance Disclosure and its Determinants in a Developing Market: The Case of Egypt. Advances in Accounting, v. 28, n. 1, p. 168-178, 2012. 
Shehata, N. F., (2016). Assessment of corporate governance disclosure in the GCC countries using the unctad isar benchmark. The Journal of Developing Areas. v. 50 n. 2, 2016.

Shiri, M. M. et al. Corporate Governance and Earning Quality : Evidence from Iran. MiddleEast. Journal of Scientific Research, v. 11, n. 6, p. 702-708, 2012.

Silva, Sabrina Soares da; Sousa, Ana Rosa de; Leite, Eduardo Teixeira. Conflito de agência em organizações cooperativas: Um ensaio teórico. Organizações Rurais \& Agroindustriais, Lavras, Minas Gerais, v. 13, n. 1, p.1-14, out. 2010. 